NASA Technical Memorandum 107177

AIAA-96-0497

\title{
Calculation of Turbulent Subsonic Diffuser Flows Using the NPARC Navier-Stokes Code
}

J.C. Dudek and N.J. Georgiadis

Lewis Research Center

Cleveland, Ohio

D.A. Yoder

University of Cincinnati

Cincinnati, Ohio

Prepared for the

34th Aerospace Sciences Meeting and Exhibit

sponsored by the American Institute of Aeronautics and Astronautics

Reno, Nevada, January 15-18, 1996

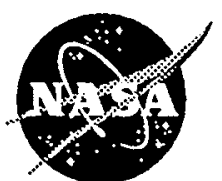

National Aeronautics and

Space Administration 


\title{
CALCULATION OF TURBULENT SUBSONIC DIFFUSER FLOWS USING THE NPARC NAVTER-STOKES CODE
}

\author{
J. C. Dudek" and N. J. Georgiadis* \\ NASA Lewis Research Center \\ Cleveland, Ohio \\ D. A. Yoder ${ }^{\dagger}$ \\ The University of Cincinnati \\ Cincinnati, Ohio
}

\begin{abstract}
Axisymmetric subsonic diffuser flows were calculated with the NPARC Navier-Stokes code in order to determine the effects various code features have on the flow solutions. The code features examined in this work were turbulence models and boundary conditions. Four turbulence models available in NPARC were used: the Baldwin-Lomax algebraic model, the Baldwin-Barth one-equation model, and the Chien k$\varepsilon$ and Wilcox $k-\omega$ two-equation models. The three boundary conditions examined were the free boundary, the mass flux boundary and the subsonic outflow with variable static pressure. In addition to boundary condition type, the geometry downstream of the diffuser was varied to see if upstream influences were present. The NPARC results are compared with experimental data and recommendations are given for using NPARC to compute similar flows.
\end{abstract}

\section{Introduction}

The NPARC Navier-Stokes $\operatorname{code}^{1}$ is used by government, industry and academia to calculate a wide variety of aerospace propulsion flows. NPARC is currently being used to calculate subsonic diffuser flows encountered in both subsonic and supersonic aircraft engine inlets. These flows are turbulent and characterized by strong adverse pressure gradients.

Predicting turbulent adverse pressure gradient flows, both with and without separation, is a challenging task for most turbulence models and flow solvers. Previous work has shown, for example, that the Baldwin-Barth one-equation model ${ }^{2}$ and the Baldwin-Lomax algebraic model ${ }^{3}$ generally under predict the shear stress for these flows, while $k-\varepsilon$ models tend to over predict wall shear stress. In flows with separation or incipient separation, this results in the Baldwin-Barth and the Baldwin-Lomax

\footnotetext{
* Aerospace Engineer, Member AIAA

${ }^{\dagger}$ Graduate Student, Student Member AIAA
}

models predicting early separation, and $\mathrm{k}-\varepsilon$ predicting late separation. $4,5,6$

Subsonic diffuser studies with the NPARC code, described herein, reinforce these turbulence model observations and emphasize the need for the capability to calculate adverse pressure gradient flows. In response to this, the $\mathrm{k}-\omega$ model of Wilcox, ${ }^{7}$ which is known to give better results for adverse pressure gradient flows, has recently been installed in NPARC. 8

The objective of this paper is to evaluate NPARC for calculating subsonic diffuser flows, with emphasis on the effects that turbulence model and boundary condition selection have on the quality of the flow solution. Two different experimental diffuser geometries are examined. The first is a diffusing pipe flow referred to as Fraser Flow A in the AFOSR-IFP-Stanford Conference Proceedings; ${ }^{9,10}$ this flow remains attached. The second geometry consists of a turbulent boundary layer developing axially on a cylinder in a wind tunnel with diverging walls. ${ }^{11,12}$ Two different pressure gradient flows were measured for this case: one which remains attached and one which is separated.

The following sections provide a brief description of the turbulence models in NPARC and a description of how NPARC was used to calculate each of the diffuser flows. The computational results are evaluated based on their agreement with experimental data. The flows examined were axisymmetric and were run using the two-dimensional NPARC code. NPARC version 2.1 was used for all calculations except those using the $\mathrm{k}-\omega$ turbulence model; these cases were run using NPARC version 2.2 .

\section{Turbulence Models in NPARC}

The turbulence models used in this study were the Baldwin-Lomax algebraic model (BL), ${ }^{3}$ the BaldwinBarth one-equation model (BB), ${ }^{2}$ the Chien low Reynolds number $k-\varepsilon \operatorname{model}^{13,14}$ and the recently 
installed Wilcox $k-\omega$ model $^{7,8}$ (both two-equation models).

The Baldwin-Lomax algebraic model is patterned after the model of Cebeci ${ }^{15}$ with modifications that avoid the necessity for finding the boundary layer edge. It is a two-layer model which makes use of the Prandtl-Van Driest formulation for the inner layer. ${ }^{3}$

The Baldwin-Barth one-equation model avoids the need for an algebraic length scale and is derived from a simplified form of the $k-\varepsilon$ equations. It solves a field equation for the turbulence Reynolds number, $R_{T}=k^{2} / v \varepsilon$.

The Chien low Reynolds number $k-\varepsilon$ model solves two transport equations - one for the turbulent kinetic energy, $k$, and one for the turbulent dissipation rate, $\varepsilon-$ with the turbulent viscosity proportional to $\mathrm{k}^{2} / \varepsilon$. The phrase, "low Reynolds number," refers to the fact that the model is applied near the solid surface where the turbulent Reynolds number and wall functions are not required.

The Wilcox $k-\omega$ model also solves two transport equations, where the second quantity, $\omega$, is the dissipation divided by the turbulent kinetic energy. This model has been shown to predict adverse pressure gradient flows, both with and without separation, better than the other three turbulence models. ${ }^{4,11}$

\section{Fraser Diffusing Pipe Flow}

The first flow case that was calculated is known as the Fraser (flow A) case from the AFOSR-IFP Stanford Conference. ${ }^{9,10}$ The geometry of the conical diffuser is shown in figure 1 . In the experiment, a length of 0.152 $m$ diameter straight pipe preceded the 5 degree half angle conical diffuser. The core flow velocity at the diffuser entrance was approximately $52 \mathrm{~m} / \mathrm{s}$ (Mach 0.15) and $\mathrm{Re}_{\theta}$, the Reynolds number based on the momentum thickness $\theta$, was approximately 3000 . Measurements of velocity profiles and skin friction were made at 11 locations in the diffuser as listed in table 1 . The first measurement station, corresponding to $\mathrm{x}=0.117 \mathrm{~m}$ (diameter $=0.154 \mathrm{~m}$ ), is slightly upstream of the beginning of the diffusing section; the last measurement station, corresponding to $x=0.642 \mathrm{~m}$ (diameter $=0.236 \mathrm{~m}$ ), is just upstream of the exit plane of the diffusing section. The diffuser exits into ambient air.

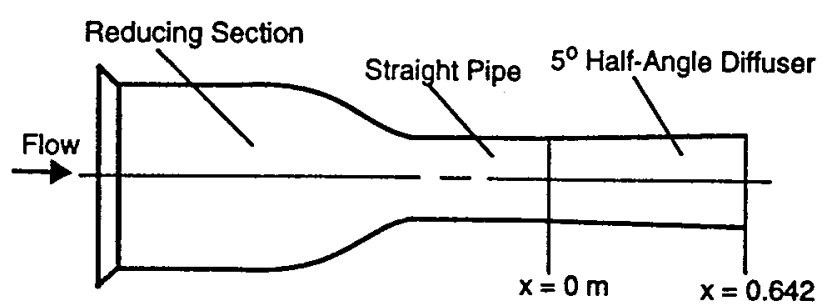

Figure 1. Schematic of Fraser Flow A experimental setup.
Table 1. Locations of velocity measurements for Fraser Flow A.

\begin{tabular}{|c|c|}
\hline Station Number & Axial Location (m) \\
\hline \hline 1 & 0.117 \\
\hline 2 & 0.158 \\
\hline 3 & 0.211 \\
\hline 4 & 0.236 \\
\hline 5 & 0.300 \\
\hline 6 & 0.381 \\
\hline 7 & 0.438 \\
\hline 8 & 0.468 \\
\hline 9 & 0.522 \\
\hline 10 & 0.578 \\
\hline 11 & 0.642 \\
\hline
\end{tabular}

\section{Computational Grids}

The baseline computational grid for this case was generated using a version of the INGRID grid generation package $^{16}$ and has 121 points in the axial direction and 71 points in the radial direction. As shown in figure 2, the grid includes a straight section of pipe both upstream and downstream of the conical diffusing section. A short circular arc transition was used between sections. The grid was packed to the solid wall such that the value of $y+$ at the first point off the wall was approximately 1 ; this value is based on the core flow velocity at the first measurement station and an assumed skin friction coefficient of 0.003 . Previous NPARC validation work indicates that this gives sufficient boundary layer resolution for wall bounded turbulent flows. ${ }^{17}$ The grid is also packed axially at the inflow boundary, as recommended in reference 17, to resolve the large axial flow gradients.

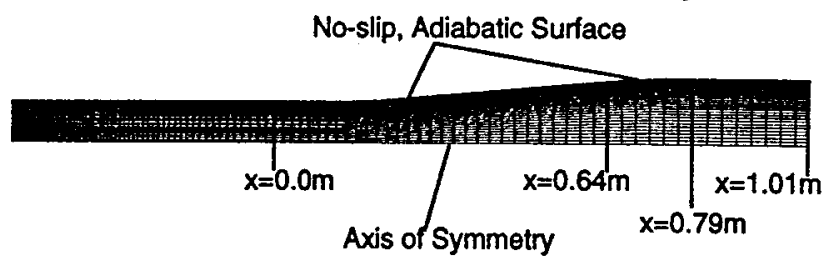

Figure 2. Baseline computational grid for Fraser Flow A.

Grids F2 and F3, shown in figure 3, were also generated, in addition to the baseline grid. These grids were different from the baseline grid primarily in the geometry downstream of the diffusing section; they were of interest because it was initially suspected that the downstream geometry had some upstream influence on the flow solutions. Grid F2 is identical to the baseline grid, except that the dimensions are $181 \times 71$, and the axial grid points are clustered both at the inflow boundary and at 
the last measurement station in the diffuser. Grid F3 has the same dimensions as grid F2, but has different packing and a different geometry downstream of the last measurement station. It is packed at the inflow boundary, the last measurement station and the outflow boundary. Instead of using a straight section downstream of the last measurement station, grid $\mathrm{F} 3$ uses an extension of the 5 degree half angle conical diffusing section.

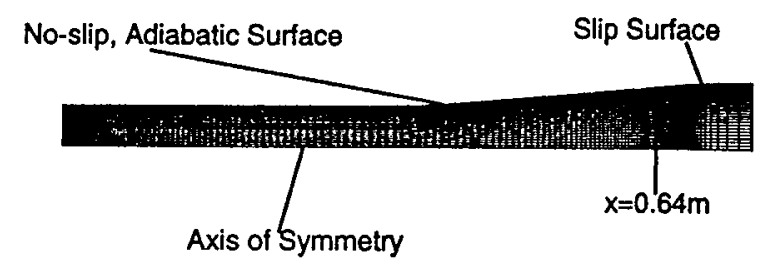

(a) Grid F2

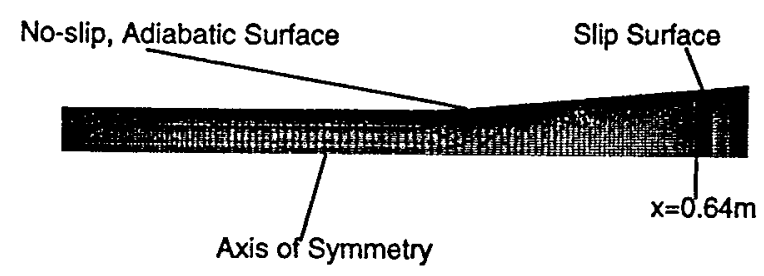

(b) Grid F3

Figure 3. Alternate computational grids for Fraser Flow A.

\section{Boundary Conditions}

For the boundary conditions, the inflow of the calculations was specified as a free boundary and placed $0.61 \mathrm{~m}$ upstream of the first measurement station in an attempt to match the momentum thickness and displacement thickness measured in the experiment at this first station. A free inflow boundary in NPARC requires the total pressure and temperature to be specified, and uses simple characteristic equations to specify the flow field. The pipe centerline boundary was specified as an axis of symmetry, and the solid boundary was specified as a noslip adiabatic surface. For calculations made using the baseline grid, the no-slip, adiabatic boundary condition was set for the entire axial length of the pipe. For calculations made using grids F2 and F3, the no-slip, adiabatic condition was set from the inflow boundary to the last measurement station in the diffuser, and a slip surface was set for the remaining axial length.

Using the Chien $k-\varepsilon$ turbulence model, the outflow location, geometry and boundary condition type were examined to determine their effect on the flow solution. Using the baseline grid and the specified mass flux boundary condition, three outflow locations were examined: (1) the last measurement station (the true diffuser exit plane), (2) $0.15 \mathrm{~m}$ downstream of the last station, and (3) $0.37 \mathrm{~m}$ downstream of the last station. These three locations are labeled in figure 2. The latter two outflows were examined because the flow solution obtained with the exit at the last measurement station did not conserve mass between the outflow grid line and the grid line just upstream. The two cases with the extended grid conserved mass and produced essentially the same solution for the quantities examined: the local skin friction coefficient, the static pressure coefficient, the integral boundary layer properties, and the velocity profiles. With the outflow at location 2 , the solutions obtained using the baseline grid and grids F2 and F3 were compared and found to have no appreciable differences.

Using the baseline grid, three different types of exit boundary conditions were examined: the free boundary, the subsonic outflow boundary with variable static pressure, and the specified mass flux boundary. These three boundary conditions all are obtained using extrapolation of the upstream flow field, but use different static pressure profiles. The free boundary uses the user-specified value of the static pressure across the entire boundary; the subsonic outflow with variable static pressure uses the user-specified value of static pressure at a specified grid point with the pressure variation across the boundary coming from the closest upstream station; and the specified mass flux boundary uses the user-specified mass flux to compute the static pressure which is then held constant across the entire boundary. All three boundary conditions produced essentially the same flow solution. For the results which follow, the exit boundary is located at $x=0.15 \mathrm{~m}$ downstream of the last station and the specified mass flux boundary condition was used.

This parametric investigation indicates that the flow solution for the Fraser subsonic diffuser is essentially independent of the outflow geometry, location and boundary condition type. The results which follow were computed using the baseline grid with the downstream boundary at location 2 , and using the specified mass flux outflow boundary condition.

\section{Artificial Viscosity}

The artificial viscosity selected in NPARC for these computations was the modified Jameson-style artificial viscosity with the Jameson-style spectral radius term. To remove any doubts that the artificial viscosity was influencing the turbulent viscous effects, the second-order artificial viscosity coefficient was set to zero, although increasing it to 0.25 (the default value) had very little effect on the flow solutions. The fourth-order coefficient 
was left at its default value of 0.64 , as recommended in the NPARC User's Guide.'

\section{Comparison of NPARC Solutions to Experimental Data}

The computational results are compared with the experimental piezometer and pitot measurements in figures 4 through 7 . The integral momentum and displacement thicknesses, $\theta$ and $\delta^{*}$, shown in figure $4 a$ and $4 b$, agree well with the experimental values at the first measurement station, indicating that the upstream boundary conditions were adequately specified. Further downstream in the diffuser, agreement is fairly good with the $k-\varepsilon, k-\omega$, and $B L$ models only slightly under predicting the displacement effects, and the BB model over predicting them. A plot of the shape factor, $\mathrm{H}$, is shown in figure $4 c$, and indicates that all four turbulence models have difficulty predicting the adverse pressure gradient effects, with the $\mathrm{BB}$ and $\mathrm{BL}$ models predicting stronger retardation effects, while both two-equation models under predict these effects. This behavior is consistent with the skin friction results of figure 5 , which indicate that $\mathrm{BB}$ predicts separation at $\mathrm{x}=0.323 \mathrm{~m}$ and $\mathrm{BL}$ predicts separation at $x=0.438 \mathrm{~m}$. The $\mathrm{k}-\varepsilon$ skin friction is much too high, whereas the $k-\omega$ results are in very close agreement with the experimental data. The pressure distribution is shown, in figure 6, where $C_{p}=2\left(p-p_{\text {ref }}\right) /\left(\begin{array}{c}\rho_{\text {ref }} u_{\text {ref }}^{2} \\ \text { refere, }\end{array}\right)$, and the reference pressure, density and velocity, $p_{\text {ref }}, \rho_{\text {ref }}$ and $u_{\text {ref }}$ are the values at station 1, just upstream of the diffusing section. In the downstream portion of the duct, BB under predicts the pressure rise while the other three turbulence models slightly over predict it; this behavior is consistent with the displacement effects shown in figure $4 \mathrm{~b}$. Three velocity profiles are shown in figure 7 corresponding to experimental stations 1,6 and 11 at $x=0.117 \mathrm{~m}, 0.381 \mathrm{~m}$ and $0.642 \mathrm{~m}$. All of the models show good agreement at station 1, with the exception of the BB model, which overshoots the experimental data near the edge of the boundary layer. Similar overshoots are also present in the NPARC validation of turbulent flow over a flat plate, ${ }^{18}$ and to a much lesser extent in the adverse pressure gradient computations of Menter. ${ }^{4}$

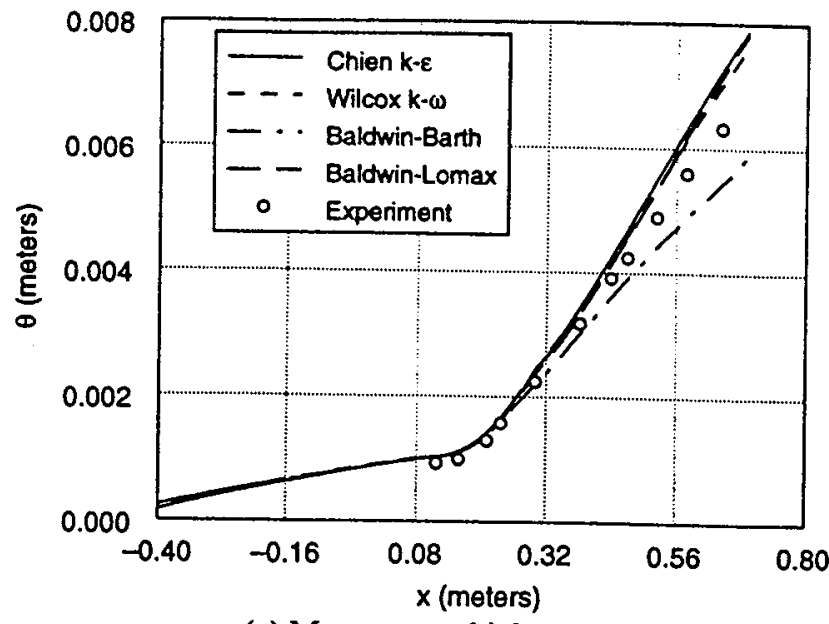

(a) Momentum thickness.

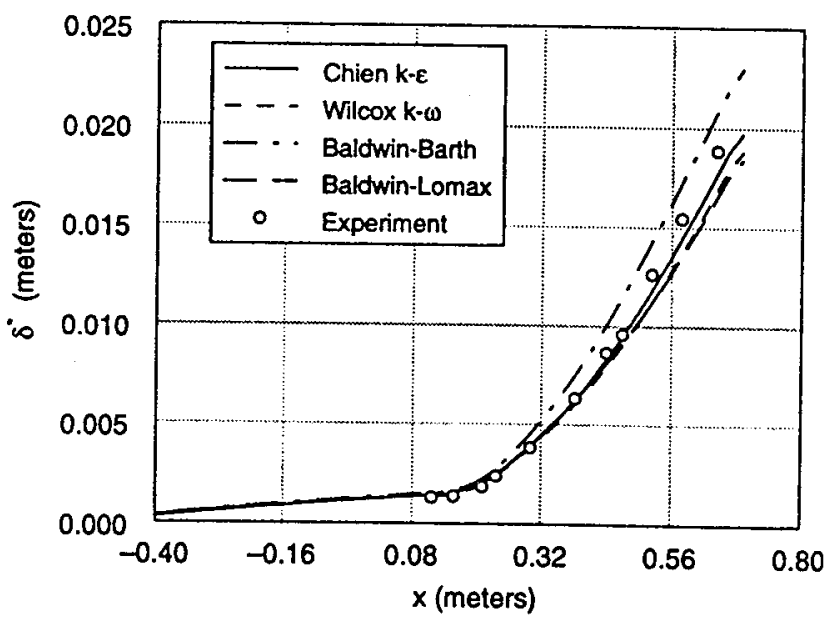

(b) Displacement thickness.

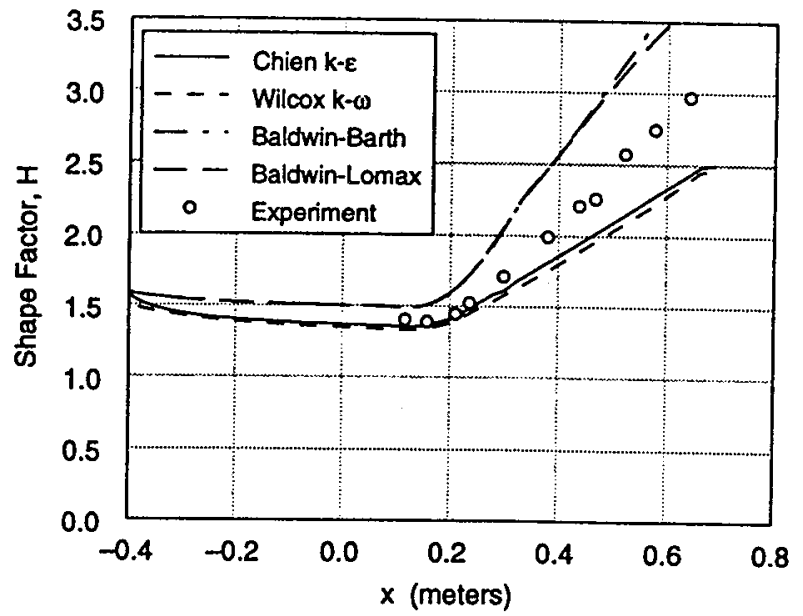

(c) Shape factor.

Figure 4. Integral boundary layer parameters for Fraser Flow A. 


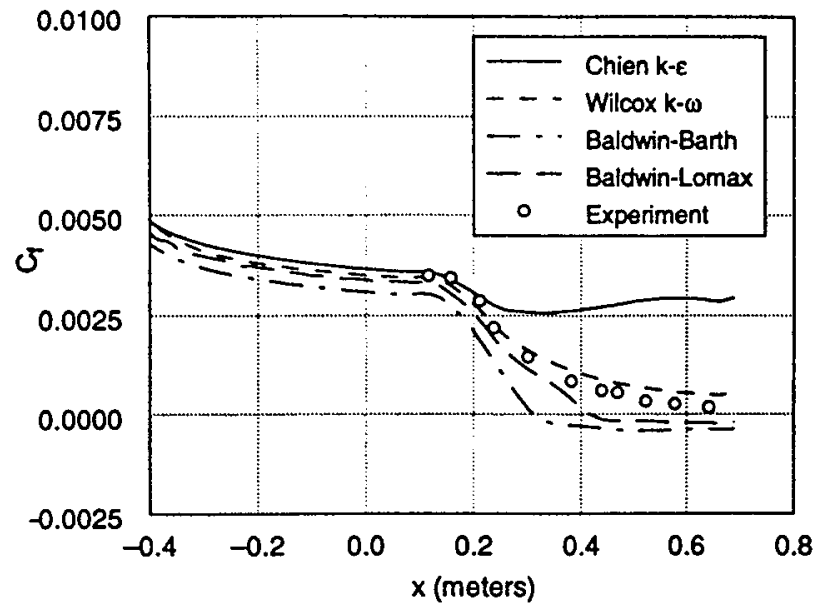

Figure 5. Local skin friction coefficient for Fraser flow A.

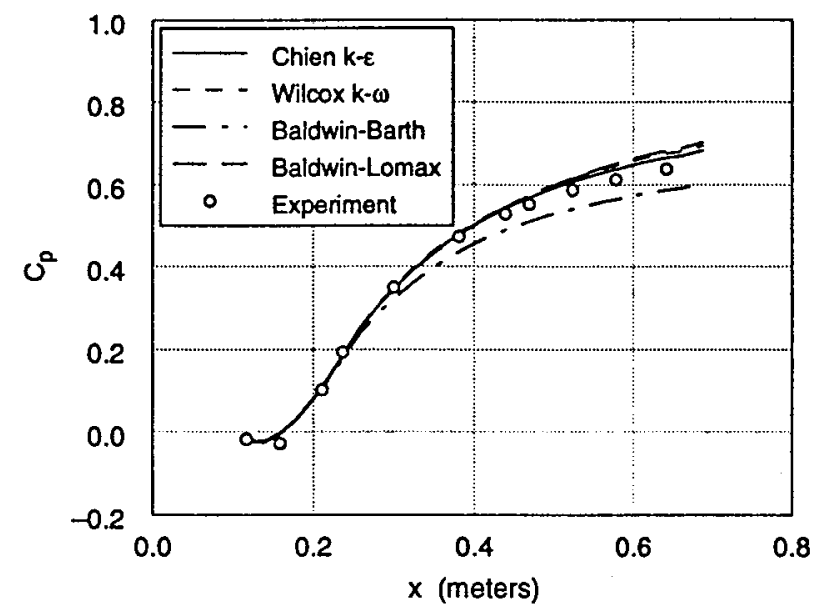

Figure 6. Static pressure coefficient for Fraser flow A.

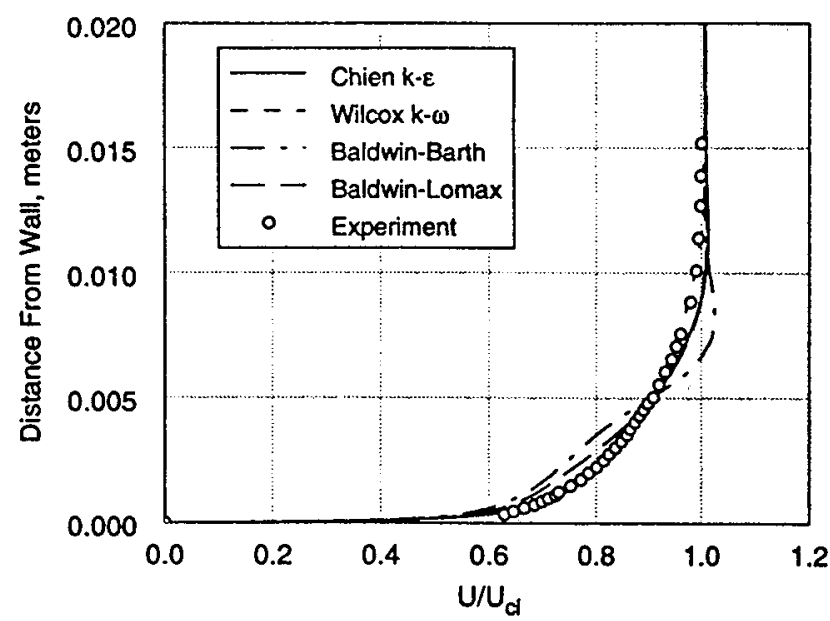

(a) $x=0.117 \mathrm{~m}$

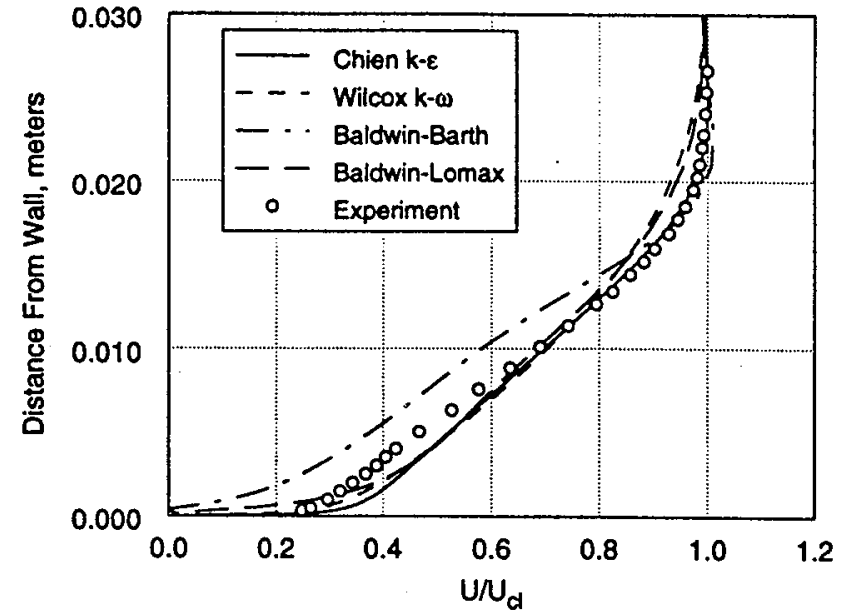

(b) $x=0.381 \mathrm{~m}$

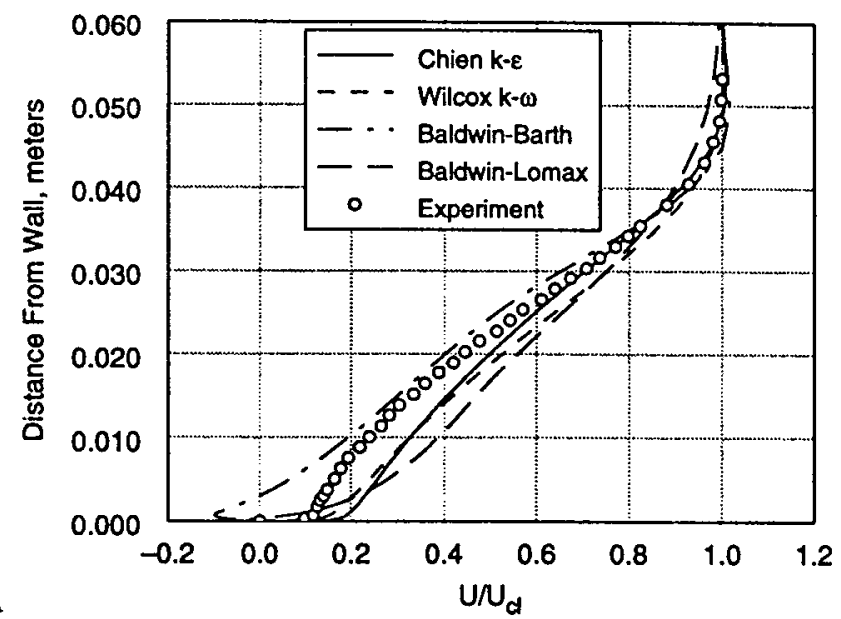

(c) $\mathrm{x}=0.642 \mathrm{~m}$

Figure 7. Velocity profiles for Fraser flow $A$ at three axial locations.

\section{Driver Adverse Pressure Gradient Flow}

This validation case models the experiments of Driver, ${ }^{11,12}$ who measured flow over a $0.140 \mathrm{~m}$ diameter cylinder, mounted axially in a wind tunnel with diverging walls. A schematic of the experimental setup is shown in figure 8. Two types of flow conditions, differing in the strength of the imposed pressure gradient, were examined. In case BS0, the flow remains attached, and in case CSO, the pressure gradient is severe enough to cause separation. The pressure gradient was imposed on the downstream portion of the flow by diverging the four tunnel walls; boundary layer suction was used to prevent separation on these walls. Detailed three-dimensional measurements were used to validate the axisymmetry of the flow. Boundary layer profiles were measured at 10 stations for case BSO, and 13 stations for case CSO, as shown in table 2 , where the imposed 
adverse pressure gradient region begins at an axial location of approximately $-0.304 \mathrm{~m}$, and the Reynolds number based on momentum thickness, $\operatorname{Re}_{\theta}$, was approximately 3000 . The tunnel was operated at atmospheric temperature, and the core flow velocity at the reference station, station 1 at $x=-0.457 \mathrm{~m}$, was $30 \mathrm{~m} / \mathrm{s}$ $(\mathrm{M}=0.087)$.

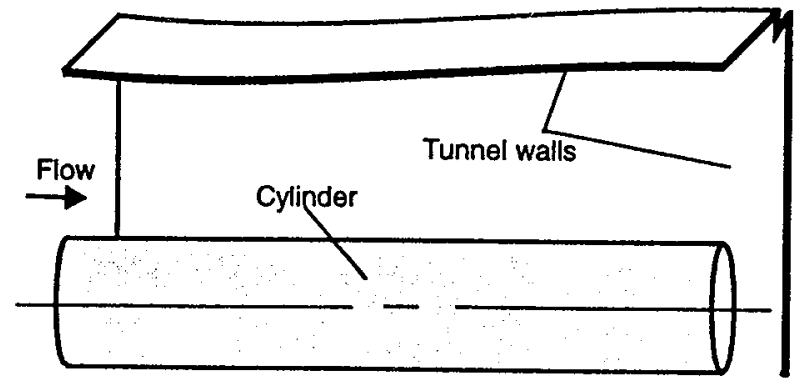

Figure 8. Schematic of Driver experimental setup.

Table 2. Locations of skin friction and velocity measurements for the Driver adverse pressure gradient experiments.

\begin{tabular}{|c|c|c|c|}
\hline \multicolumn{2}{|c|}{ Case $\quad$ BS0 } & \multicolumn{2}{|c|}{ Case CSO } \\
\hline $\begin{array}{c}\text { Station } \\
\text { Number }\end{array}$ & $\begin{array}{c}\text { Axial } \\
\text { Location } \\
(\mathrm{m})\end{array}$ & $\begin{array}{c}\text { Station } \\
\text { Number }\end{array}$ & $\begin{array}{c}\text { Axial } \\
\text { Location } \\
(\mathrm{m}) \\
\end{array}$ \\
\hline 1 & -0.457 & 1 & -0.457 \\
\hline 2 & -0.330 & 2 & -0.330 \\
\hline 3 & -0.229 & 3 & -0.229 \\
\hline 4 & -0.152 & 4 & -0.152 \\
\hline 5 & -0.076 & 5 & -0.076 \\
\hline 6 & -0.013 & 6 & -0.013 \\
\hline 7 & 0.013 & 7 & 0.013 \\
\hline 8 & 0.152 & 8 & 0.025 \\
\hline 9 & 0.229 & 9 & 0.051 \\
\hline 10 & 0.305 & 10 & 0.102 \\
\hline & & 11 & 0.152 \\
\hline & & 12 & 0.229 \\
\hline & & 13 & 0.305 \\
\hline
\end{tabular}

\section{Computational Grids}

The computational grids for this case, one for case BSO and one for case CSO, were also generated using the INGRID grid generation package and had 181 points in the axial direction and 71 points in the radial direction. These grids also included a straight section of pipe both upstream and downstream of the diffusing sections, as shown in figure 9 . The upstream length of pipe, $0.6 \mathrm{~m}$ in length, was chosen in order to match the momentum thickness at the first measurement station; the downstream length of pipe, $0.47 \mathrm{~m}$ in length, was chosen to be similar in proportion to the downstream length of pipe in the Fraser baseline grid. To define the inviscid boundary, opposite the cylinder surface, the inviscid streamlines, available from the experimental data, were used. The intended use of this experimental streamline data was for definition of the far field boundary for axisymmetric computations. This was needed because the flow field around the cylinder was axisymmetric, though the test section was not. These streamlines were a distance of approximately one to two boundary layer thicknesses from the cylinder, so they were translated to increase this distance to approximately four to five boundary layer thickness, which was more desirable in NPARC. The velocity measurements at each station were used when translating the streamlines to insure that the same amount of mass flux was added at each station. These new translated streamlines were then curve fitted, using cubic spline interpolation, to give a smooth curve. Streamline data was available at only 10 stations for case BS0 and 13 stations for case CSO. There is some question as to whether or not this amount of data was sufficient to accurately define the test geometry in the computational grid. The grid was packed both axially at the inflow boundary and radially at the cylinder surface, as described for the Fraser baseline grid.

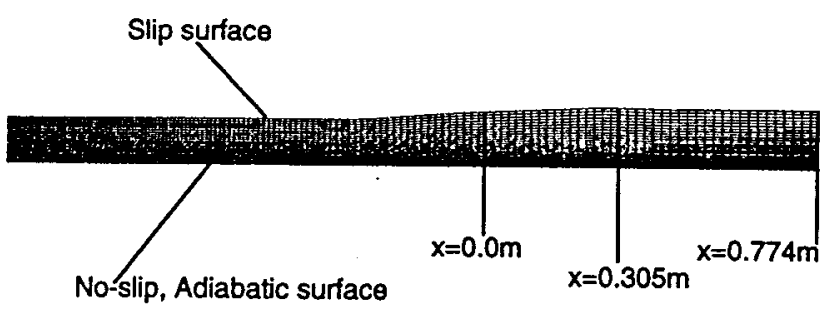

(a) Case BSO

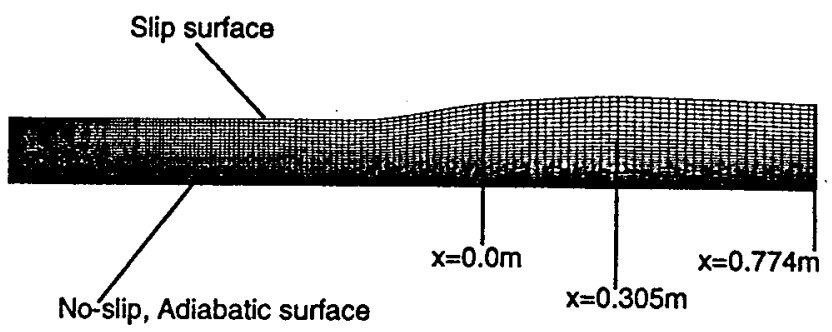

(b) Case CSO

Figure 9. Computational grids for Driver cases BSO and CSO. 


\section{Boundary Conditions}

The boundary conditions for this case were similar to those set for the Fraser case, except for the inviscid streamline boundary, which was set to be a slip surface.

\section{Artificial Viscosity}

The second order artificial viscosity coefficient was set to 0.01 , and the fourth-order coefficient, was $\mathbf{0 . 6 4}$.

\section{Comparison of NPARC Solutions to Experimental Data}

The computational results are compared with experimental laser-doppler velocimeter and oil-flow laser interferometer data in figures 10 through 13 for case BSO and figures 14 through 17 for case CSO. The quantitative relationships between turbulence models are similar to the Fraser flow A results; however, the agreement with the experimental data differs somewhat.

For case BS0, the integral momentum and displacement thicknesses are shown in figure 10; the agreement with experimental data is good in the upstream portion of the diffuser. However, both quantities are under predicted in the downstream portion of the diffuser, indicating an under prediction of the strength of the adverse pressure gradient. BB did a better job of predicting the adverse pressure gradient effects, as shown by the shape factor, figure 10, than the other three models which all showed significantly lower $\mathrm{H}$ values. The skin friction results, shown in figure 11 , indicate that all models predict attached flow in the duct, with $k-\varepsilon$ predicting the highest shear stresses, followed by $k-\omega, B L$, and $B B$, which is in closest agreement to the data. All of the models under predict $C_{p}$ in the adverse pressure gradient region of the duct by approximately the same amount, as shown in figure 12 . Three velocity profiles are shown in figure 13 at experimental stations 1,5 and 10 , at $x=-$ $0.457 \mathrm{~m},-0.076 \mathrm{~m}$, and $0.305 \mathrm{~m}$. All models give fairly good agreement with the data at the first experimental station, with the agreement degrading further downstream in the duct.

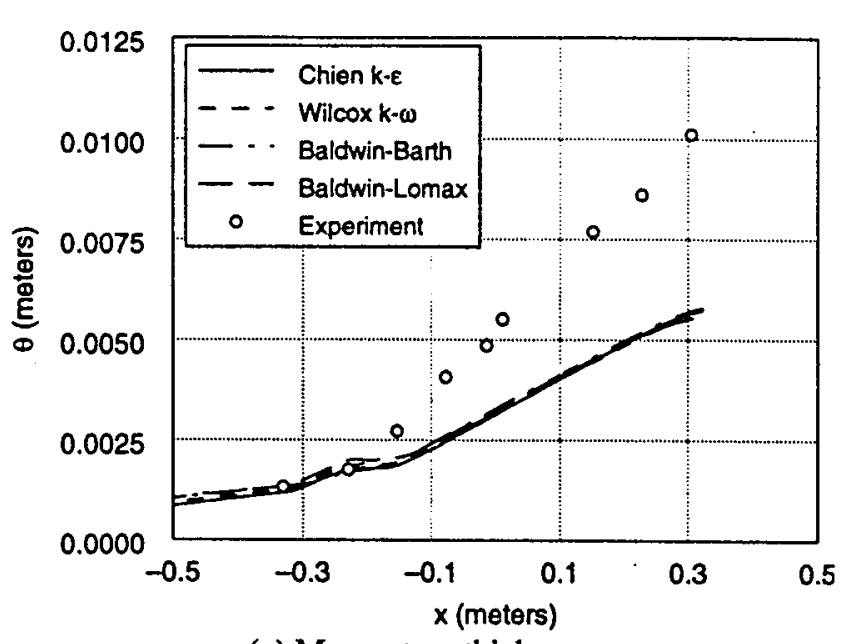

(a) Momentum thickness.

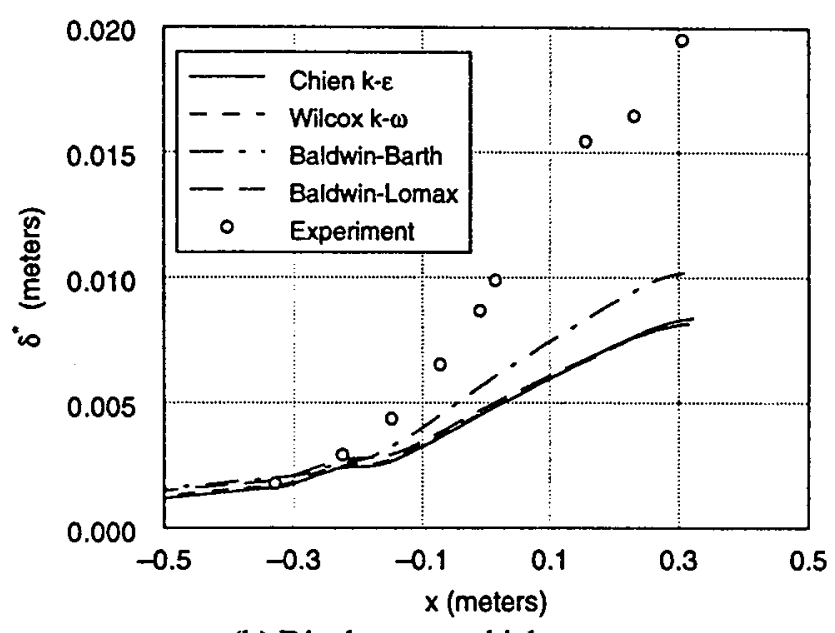

(b) Displacement thickness.

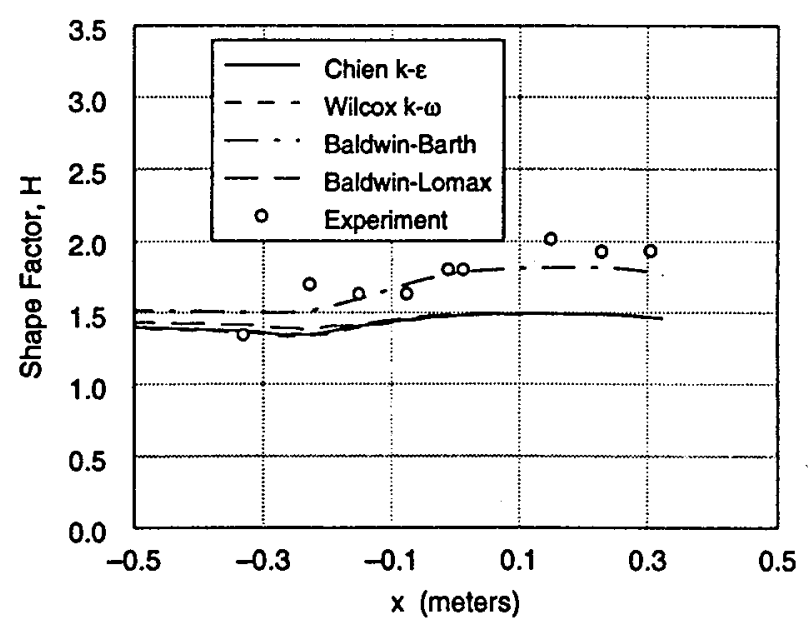

(c) Shape factor.

Figure 10. Integral boundary layer parameters for Driver case BSO. 


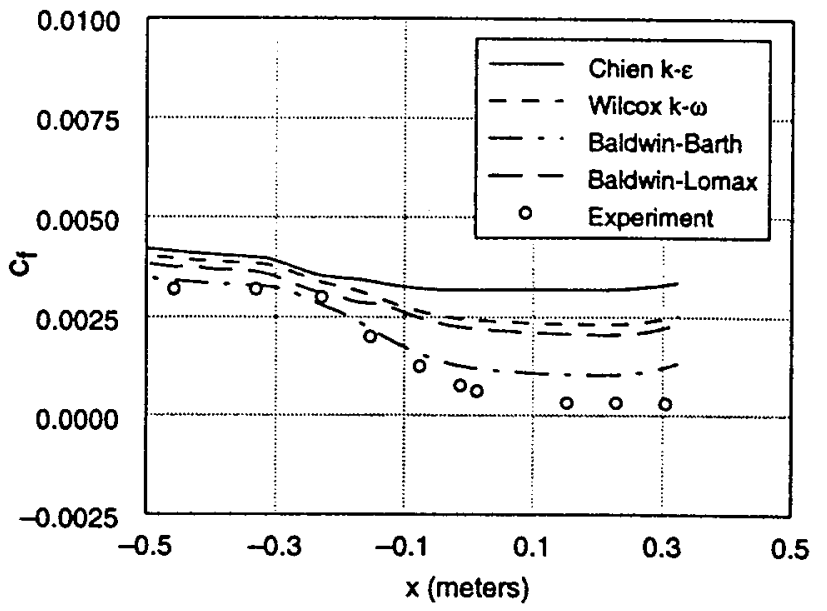

Figure 11. Local skin friction coefficient for Driver case BSO.

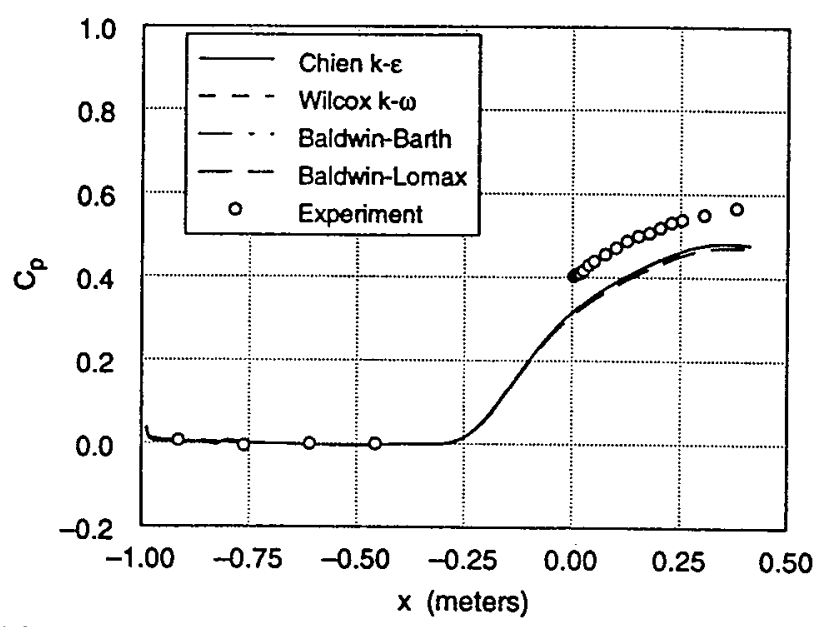

Figure 12. Static pressure coefficient for Driver case BSO.

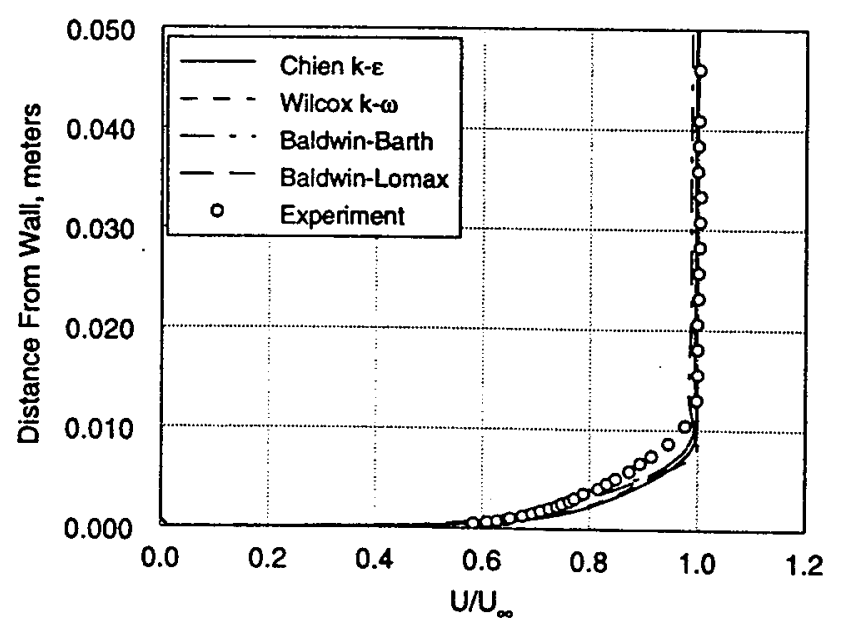

(a) $x=-0.457 \mathrm{~m}$

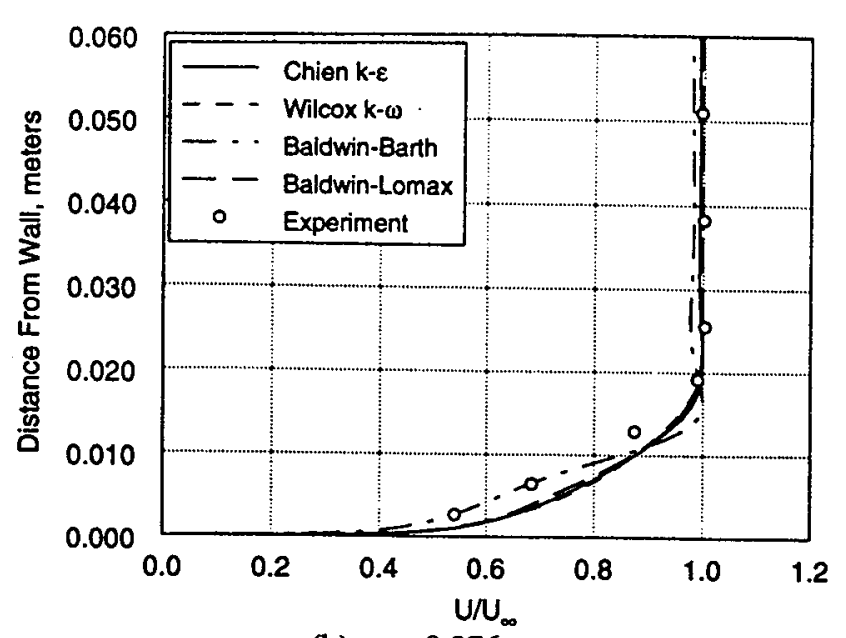

(b) $x=-0.076 \mathrm{~m}$

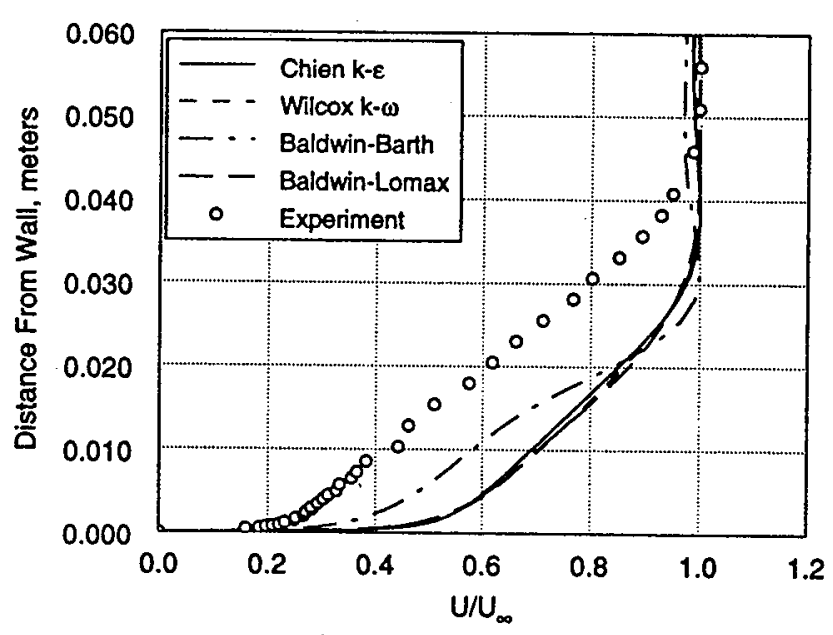

(c) $\mathrm{x}=0.305 \mathrm{~m}$

Figure 13. Velocity profiles for Driver case BSO at three axial stations.

In case CSO, the displacement and momentum thicknesses, shown in figure 14, were also under predicted in the downstream portion of the duct, with BB predicting the highest displacement thickness and therefore the largest response to the adverse pressure gradient. All models do a better job of predicting the momentum thickness than they did for case BSO. Figure $14 \mathrm{c}$ shows that all models under predict the shape factor with BB giving the highest values, indicating separated flow; the other models all give fairly flat profiles. This is consistent with the skin friction data shown in figure 15 , in which BB is the only model which predicts separation, with a separation bubble beginning at $x=-0.079 \mathrm{~m}$ and ending at $x=0.286 \mathrm{~m}$. In the experiment, the flow detached in the vicinity of $x=-0.030 \mathrm{~m}$ and reattached in the vicinity of $x=0.200 \mathrm{~m}$. The trend in the local skin friction coefficient is the same as the other two cases, 
with BB predicting the lowest skin friction, and BL, $\mathrm{k}-\omega$ and $k-\varepsilon$ predicting successively higher values. The pressure coefficient, shown in figure 16 , was predicted fairly well by all of the turbulence models, and significantly better than the case BSO results. The velocity profiles at stations 1,5 and 13 are shown in figure 17 , and the agreement with experimental data is similar to the results for cases BSO and Fraser flow A.

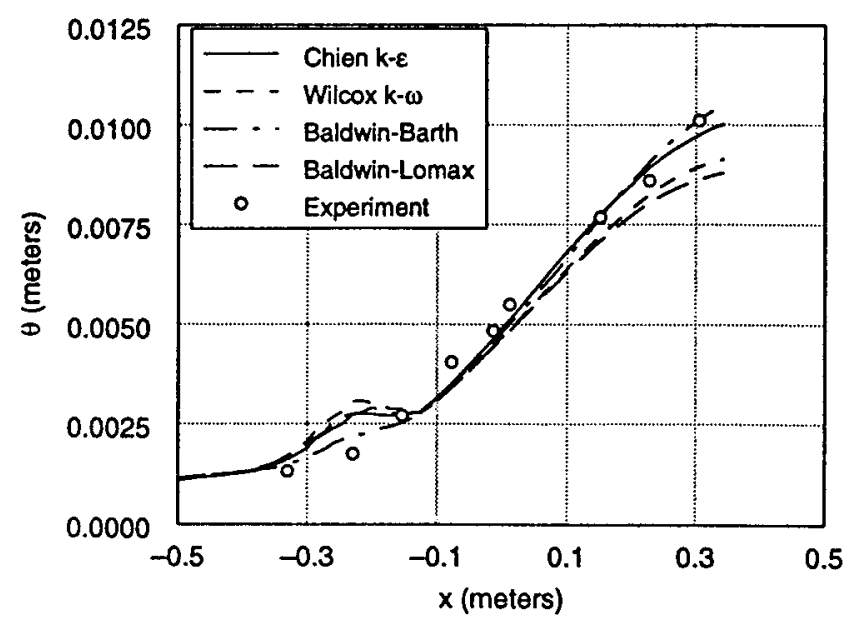

(a) Momentum thickness.

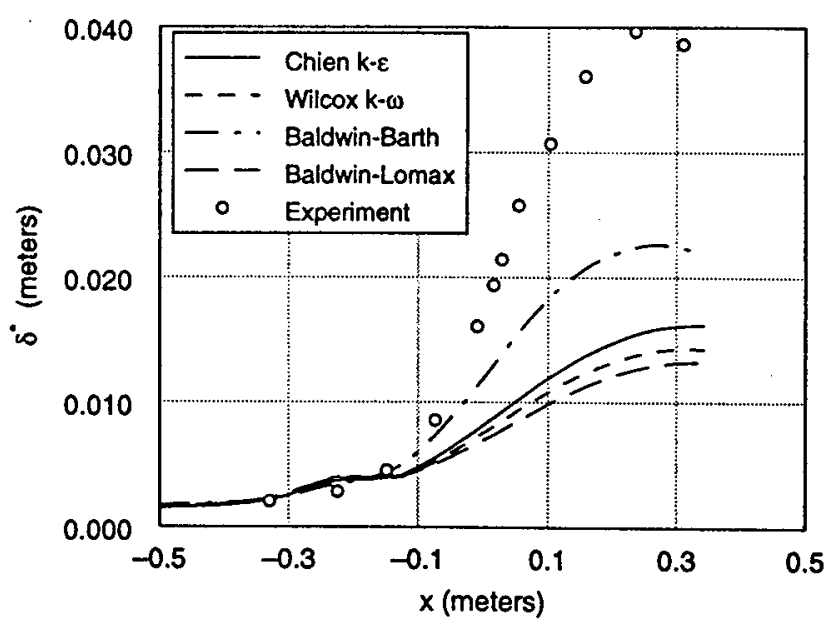

(b) Displacement thickness.

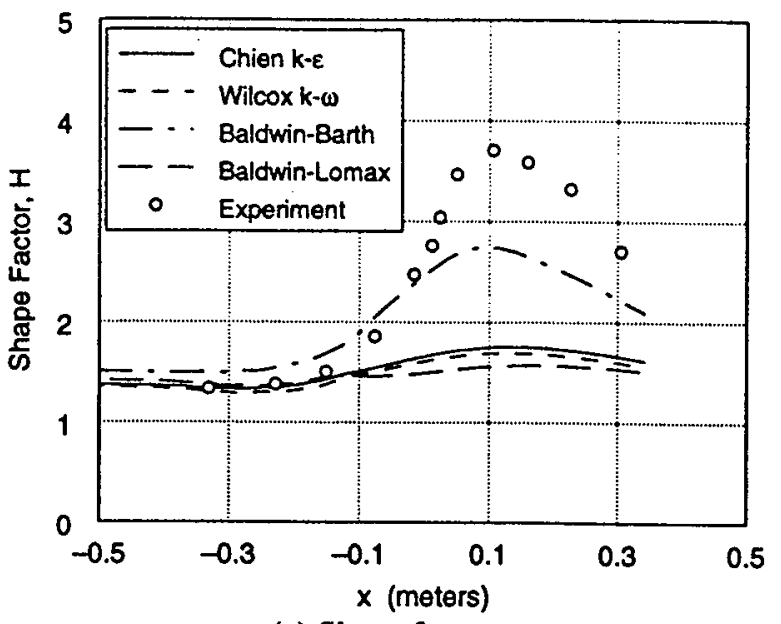

(c) Shape factor.

Figure 14. Integral boundary layer parameters for Driver case CSO.

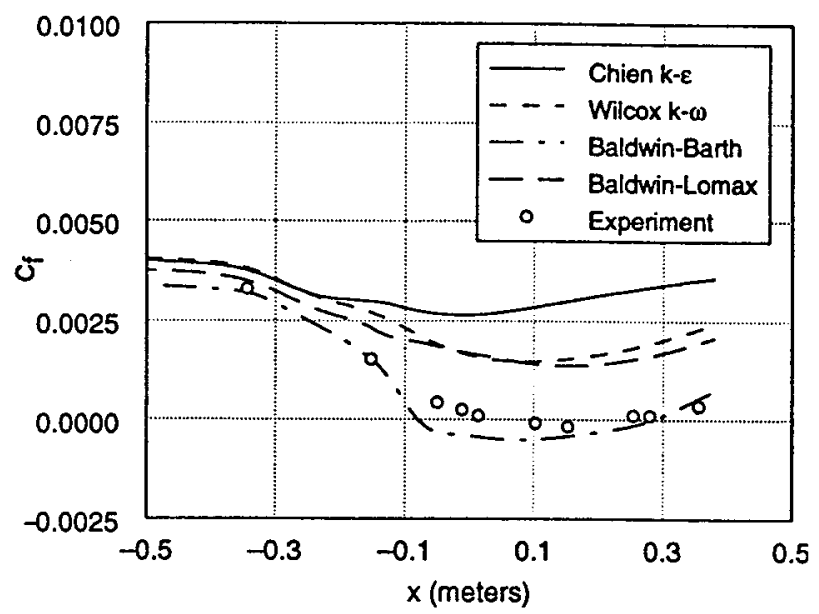

Figure 15. Local skin friction coefficient for Driver case CSO.

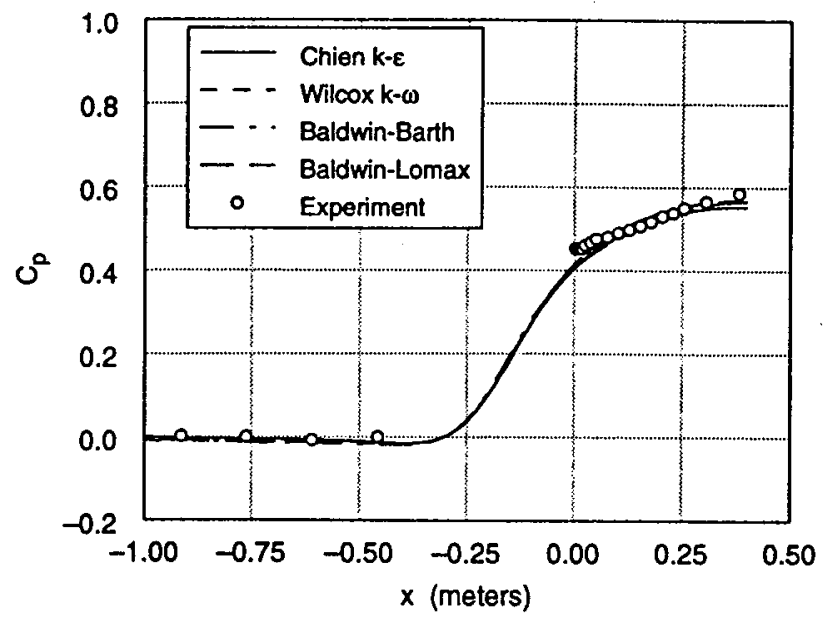

Figure 16. Static pressure coefficient for Driver case CSO. 


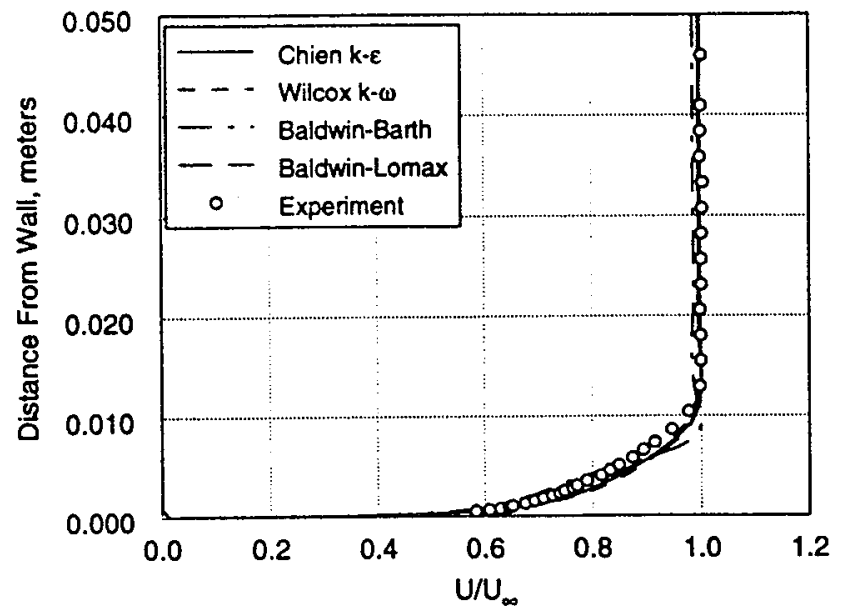

(a) $x=-0.457 \mathrm{~m}$

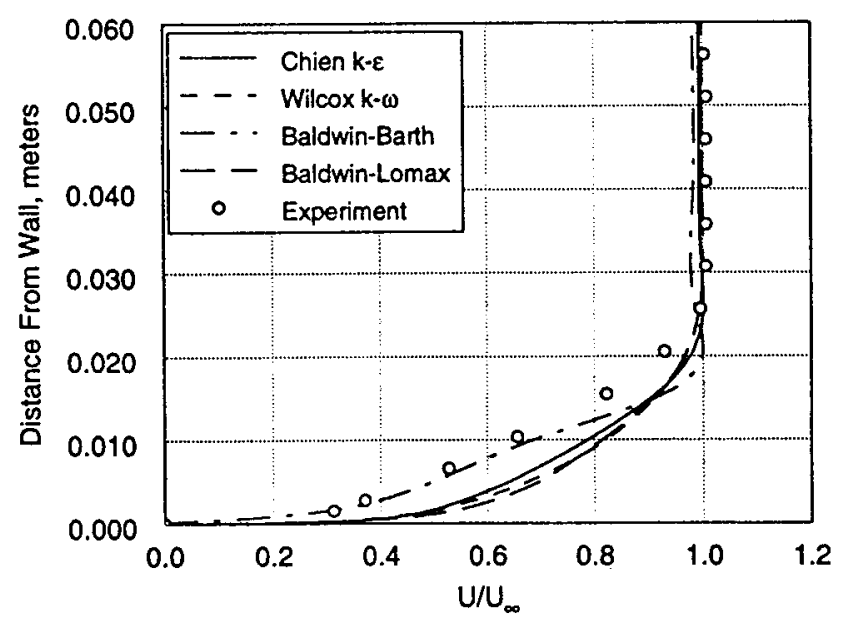

(b) $x=-0.076 \mathrm{~m}$

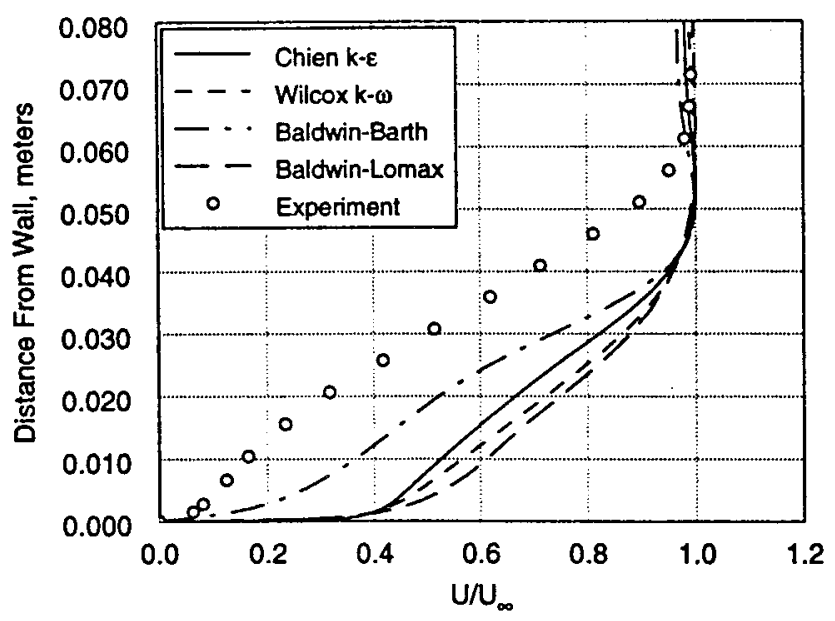

(c) $x=0.305 \mathrm{~m}$

Figure 17. Velocity profiles for Driver case CS0 at three axial stations.

\section{Discussion of Results}

For the Fraser flow A conical diffuser case, three different outflow boundary conditions were used: the free boundary, the subsonic outflow boundary with variable static pressure, and the specified mass flux boundary. All gave valid answers, and may be considered appropriate for use with subsonic diffuser flow. The geometry downstream of the diffusing section was varied as well. All geometries worked well, with the exception of the baseline grid ending at the diffuser exit; this grid did not conserve mass near the exit boundary.

The Fraser and Driver test cases were run using the $k$ $\varepsilon, k-\omega, B B$, and BL models. The Fraser solutions were similar to the results of Menter, ${ }^{4}$ but the Driver results showed some differences. The trends were similar for the displacement thickness, skin friction, and velocity. The results differed for the momentum thickness, shape factor and static pressure coefficient. The skin friction results indicate that NPARC's ability to predict separation is fairly unreliable. For example, the $k-\varepsilon$ model predicted shear stresses which are too high, and therefore it will be likely to predict attached flow when the flow is actually separated. The k- $\omega$ model also tended to predict high values of the skin friction coefficient; however, in the Fraser case, it was in best agreement with the experimental data, whereas in the Driver case, it failed to predict the separation for case CSO. The BB and BL models bracketed the experimental skin friction values, both incorrectly predicting separation for the Fraser flow, and predicting high values for the Driver BSO case. Of all of the models, BB was in the best agreement with the Driver experimental data; it was the only model which accurately predicted separation for the Driver CSO case, while all the other models predicted overly high values of shear stress.

In evaluating these results, some of the factors leading to uncertainties should be mentioned. Firstly, the differences in experimental measurement techniques should be noted. The Fraser data was taken with well-proven but less sophisticated measuring equipment (pitot tubes and piezometers) than was used to take the Driver data (LDV). Another consideration is the quality of the computational simulation of the experimental conditions. The diffusing section for the Fraser flow case was well defined, a straight 5 degree half-angle conical diffuser; whereas the Driver diffuser geometry had more uncertainty because it was defined from the experimental streamlines available only at the defined measurement stations. Ambiguities in the use of this data, for example in the quality and smoothness of the curve fit, may have led to the simulation of a pressure gradient different from the experimentally imposed gradient. These fac- 
tors bring to light the possibility that the inconsistencies in the validation results may be partially due to the quality and usage of the experimental data.

\section{Conclusions}

The NPARC Navier-Stokes code was applied to axisymmetric subsonic diffuser flows in order to evaluate the effects of various code features. The emphasis of the study was on olitflow boundary condition type, the geometry downstream of the diffusing section, and the turbulence model used. The results showed that all three outflow boundary conditions - the free boundary, the specified mass flux boundary, and the subsonic outflow boundary with variable static pressure - work well for this type of flow problem. All of the downstream geometries examined also worked equally well, with the exception of the Fraser flow baseline grid which ends at the last measurement station. The four turbulence models available in NPARC - the Baldwin-Lomax (algebraic model), the Baldwin-Barth (one equation model), and the Chien $k-\varepsilon$ and Wilcox $k-\omega$ (two equation models) were all examined and gave less conclusive results, with the $k-\varepsilon$ model over-predicting the shear stresses in all cases, and the other models varying in performance.

\section{References}

1. NPARC Alliance at NASA Lewis Research Center and Arnold Engineering Development Center, "A User's Guide to NPARC, Version 2.0," November 1, 1994.

2. Baldwin, B. S. and Barth T. J., "A One-Equation Turbulence Transport Model for High Reynolds Number Wall-Bounded Flows," AIAA Paper 910610, January 1991.

3. Baldwin, B. and Lomax, H., "Thin Layer Approximation and Algebraic Model for Separated Turbulent Flows," AIAA Paper 78-257, January 1978.

4. Menter, F. R., "Performance of Popular Turbulence Models for Attached and Separated Adverse Pressure Gradient Flows," AIAA Journal, Vol. 30, No. 8, August 1992, pp. 2066-2072.

5. De Henau, V., Raithby, G. D., and Thompson, B. E., "Prediction of Flows With Strong Curvature and Pressure Gradient Using The k- $\varepsilon$ Turbulence Model," Transactions of the ASME, Vol. 112, March 1990, pp. 40-47.

6. Rodi, W., and Scheuerer, G., "Scrutinizing the k- $\varepsilon$ Turbulence Model Under Adverse Pressure Gradient Conditions," Transactions of the ASME, Vol. 108, June 1986, pp. 174-179.
7. Wilcox, D. C., "Simulation of Transition with a Two-Equation Turbulence Model," AIAA Journal, Vol. 32, no. 2, February 1994.

8. Yoder, D. A., Georgiadis, N. J., and Orkwis, P. D., "Implementation of a Two-Equation $k-\omega$ Turbulence Model in NPARC," AIAA paper 96-0383, January 1996.

9. Fraser, H. R., "Flow A." Proceedings, AFOSR-IFPStanford Conference on Computation of Turbulent

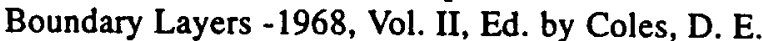
and Hirst, E. A., 1968, pp. 451-465.

10. Fraser, H. R., "The Turbulent Boundary Layer in a Conical Diffuser," Journal of the Hydraulics Division, Proceedings of the American Society of Civil Engineers, pp. 1684-1-17, June 1958.

11. Driver, D. M., "Reynolds Shear Stress Measurements in a Separated Boundary Layer Flow," AIAA Paper 91-1787, 1991.

12. Driver, D. M., and Johnson, J. P., "Experimental Study of a Three-Dimensional Shear-Driver Turbulent Boundary Layer with Streamwise Adverse Pressure Gradient," NASA TM 102211, May 1990.

13. Chien, K. Y., "Predictions of Channel and Boundary-Layer Flows with a Low-Reynolds-Number Turbulence Model," AlAA Journal, Vol. 20, No. 1, January 1982, pp.33-38.

14. Georgiadis, N. J., Chitsomboon, T. and Zhu, J., "Modification of the Two-Equation Turbulence Model in NPARC to a Chien Low-Reynolds Number k- $\varepsilon$ Formulation," NASA TM 106710, September 1994.

15. Cebeci, T., "Calculation of Compressible Turbulent Boundary Layers with Heat and Mass Transfer," AIAA Paper 70-741, June 1970.

16. Dowell, E. W. Jr. and McClure, M. D., “3D INGRID: Interactive Three-Dimensional Grid Generation," AEDC-TR-87-40, 1988.

17. Georgiadis, N. J., Dudek, J. C., and Tierney, T., "Grid Resolution and Turbulent Inflow Boundary Condition Recommendations for NPARC Calculations," AIAA Paper 95-2613, July 1995.

18. Towne, C. E., "NPARC Validation - Incompressible Turbulent Flow Past a Flat Plate," NPARC Validation Archive, http://info.arnold.af.mil/nparc/archive/ model/fpturb, September 1995. 
Public reporting burden for this collection of information is estimated to average 1 hour per response, including the time for reviewing instructions, searching existing data sources, gathering and maintaining the data needed, and completing and reviewing the collection of information. Send comments regarding this burden estimate or any other aspect of this collection of Information, including suggestions for reducing this burden, to Washington Headquarters Services, Directorate for Information Operations and Reports, 1215 Jefferson Davis Highway, Suite 1204, Arlington, VA 22202-4302, and to the Office of Management and Budget, Paperwork Reduction Project (0704-0188), Washington, DC 20503.

\begin{tabular}{|c|c|c|}
\hline 1. AGENCY USE ONLY (Leave blank) & $\begin{array}{l}\text { 2. REPORT DATE } \\
\text { February } 1996\end{array}$ & $\begin{array}{l}\text { 3. REPORT TYPE AND DATES COVERED } \\
\text { Technical Memorandum }\end{array}$ \\
\hline
\end{tabular}

Calculation of Turbulent Subsonic Diffuser Flows Using the NPARC Navier-Stokes Code

6. AUTHOR(S)

WU-505-62-52

J.C. Dudek, N.J. Georgiadis, and D.A. Yoder

7. PERFORMING ORGANIZATION NAME(S) AND ADDRESS(ES)

8. PERFORMING ORGANIZATION REPORT NUMBER

National Aeronautics and Space Administration

Lewis Research Center

Cleveland, Ohio 44135-3191

E-10139

9. SPONSORING/MONITORING AGENCY NAME(S) AND ADDRESS(ES)

10. SPONSORING/MONITORING AGENCY REPORT NUMBER

National Aeronautics and Space Administration

Washington, D.C. 20546-0001

NASA TM-107177

AIAA-96-0497

\section{SUPPLEMENTARY NOTES}

Prepared for the 34th Aerospace Sciences Meeting and Exhibit sponsored by the American Institute of Aeronautics and Astronautics, Reno, Nevada, January 15-18, 1996. J.C. Dudek and N.J. Georgiadis, NASA Lewis Research Center; D.A. Yoder, University of Cincinnati, Cincinnati, Ohio. Responsible person, J.C. Dudek, organization code 2660, (216) 433-2188.

12a. DISTRIBUTIONAVAILABILITY STATEMENT

Unclassified - Unlimited

Subject Category 02

This publication is available from the NASA Center for Aerospace Information, (301) 621-0390.

13. ABSTRACT (Maximum 200 words)

Axisymmetric subsonic diffuser flows were calculated with the NPARC Navier-Stokes code in order to determine the effects various code features have on the flow solutions. The code features examined in this work were turbulence models and boundary conditions. Four turbulence models available in NPARC were used: the Baldwin-Lomax algebraic model, the Baldwin-Barth one-equation model, and the Chien $k-\varepsilon$ and Wilcox $k-\omega$ two-equation models. The three boundary conditions examined were the free boundary, the mass flux boundary and the subsonic outflow with variable static pressure. In addition to boundary condition type, the geometry downstream of the diffuser was varied to see if upstream influences were present. The NPARC results are compared with experimental data and recommendations are given for using NPARC to compute similar flows.

\section{SUBJECT TERMS}

Diffusers; Axisymmetric flow; Subsonic flow; Turbulent flows; Turbulence models;

Boundary conditions; Incompressible flow; Computational fluid dynamics

17. SECURITY CLASSIFICATION OF REPORT Unclassified

\section{SECURITY CLASSIFICATION OF THIS PAGE Unclassified}

19. SECURITY CLASSIFICATION OF ABSTRACT Unclassified
15. NUMBER OF PAGES

13

16. PRICE CODE

$\mathrm{A} 03$

20. LIMITATION OF ABSTRACT

Standard Form 298 (Rev. 2-89)

Prescribed by ANSI SId. Z39-18 298-102 
National Aeronautics and

Space Administration

\section{Lewis Research Center}

21000 Brookpark Rd.

Cleveland, OH 44135-3191

Official Business

Penalty for Private Use $\$ 300$

POSTMASTER: If Undeliverable - Do Not Return 